\title{
Leadership in international Information Technology projects - cross-cultural considerations for Japan and India
}

\author{
Dr Pooja Sardeshmukh ${ }^{1}$, Zhivko Stoyanov ${ }^{2}$, \\ Mattias Hallberg ${ }^{3}$ \\ ${ }^{123}$ Rakuten Inc, Japan
}

\begin{abstract}
This paper describes the leadership challenges in Information Technology projects outsourced from Japan to India. During execution of such projects, project team members have to deliver under pressure with tight deadlines. At the same time, they face the multiple cultural gaps which hinder the collaboration between the two teams.

We report here some observations on real life project stories and conclude with suggestions for developing effective leaders for project management between Japan and India.
\end{abstract}

Keywords: Japanese Outsourcing, India, Cultural gap, Software development, Project Management, Japan, Infrastructure, Information Technology

Dr Pooja Sardeshmukh1

Rakuten Inc, Japan

\section{Introduction}

With rapid globalization of all industries all over the world, international projects in information technology are very common. This century has seen the growth and expansion of businesses across countries, beyond borders. Here we focus on international software projects wherein the software development is outsourced to a different country. More specifically the scope is to consider the outsourcing between Japan - the customer country outsourcing software development and India - the outsourced country where software is exclusively developed for the customer.

As compared to the software outsourcing from the USA and other countries, there has not been much of reference material available between India and Japan due to the language barriers faced by both sides' people. Another reason is also due to emphasize on the business/industry implementation of projects rather than (paper and conference) research presentation on the ways or concepts of outsourcing from Japanese industries. This paper focuses on challenges faced by persons in leadership role in an 
international project where there is a difference in business and social culture in the two countries.

\section{Purpose}

This study aims to investigate the issues faced by both side leaders referred to as project managers namely from Japan and India, thereby to understand the clear concerns on both sides. We also aim to suggest a better way of working for success of outsourced projects from Japan to India.

\section{About Rakuten}

Rakuten, Inc. (楽天株式会社 Rakuten Kabushiki-gaisha)

[1] is a Japanese electronic commerce and Internet company based in Tokyo, Japan. Initially started as just Rakuten Ichiba (market place) company, at present it has become a major global group in ecommerce serving wide variety of needs in the global market, addressing services included in the e-commerce mall such as eBooks \& eReading, travel, banking, securities, credit card, e-money, portal and media, online marketing and professional sports.

Rakuten Group of companies is constantly growing globally through acquisitions and currently has operations throughout Asia, Europe, the Americas, and Oceania. It's B2B2C[2] e-commerce platform- Rakuten Ichiba -is the largest e-commerce site in Japan and among the world's largest by sales.[3]

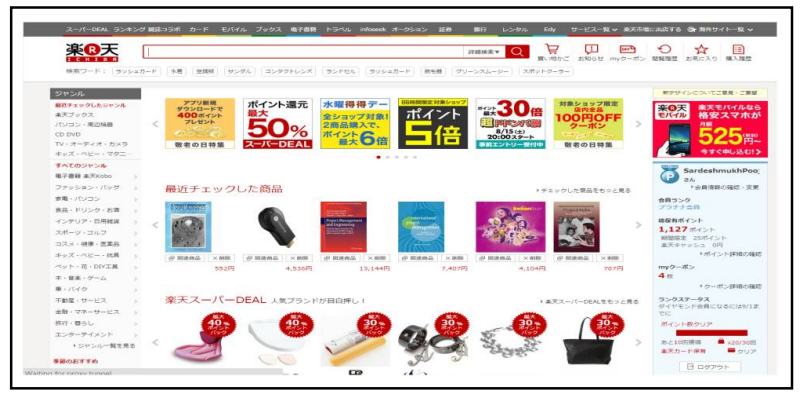

Figure 1. Rakuten Ichiba Japanese website.

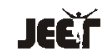

Meaning of Ichiba in Japanese language is Market place. Meaning of Rakuten in Japanese is optimism. This Rakuten Ichiba has indeed brought lot of hope in the lives of distant shop owners by helping them sell their items over the internet thereby gaining popularity for their products and extra money for themselves.

Figure 1 here shows the Japanese language interface of Rakuten Ichiba Japanese website. As can be seen here, common to any other ecommerce website it has the menu on left side as well as on the top, a search bar and the login, cart details on top as well as on the right side. The main body has information on many popular products or products related to your recent purchase. The Rakuten vision is "Empowering People and Society Striving to Become the World's No.1 Internet Services Company”. The Rakuten Ecosystem and membership database form the basis of Rakuten business, but it also offers its members fun and convenient online shopping and service experiences"'[4], [5], [6]

To get the Ichiba platform working, there are large teams working inside Rakuten Inc, the Japan head office of Rakuten. In Rakuten Inc, Japan, there are many project managers of various nationalities dealing with outsourcing of projects to Indian teams located in India. When the projects are outsourced to India, and some difficult requirements like developing an App for a Rakuten service, or writing code to fix issues on the Ichiba website etc., are to be done in India, the project managers face challenges based on the language and culture of the company where work is outsourced. As the challenges result in delivery 


\section{Japan and India distinguishing factors}

- India is 9 times bigger than Japan

- Indian population is 97 times bigger than Japan

- Indian life expectancy is 0.8 times (about 20 years) less than Japan

- Indian health expenditure is just $1.2 \%$ of Japan

- Indian Electricity consumption is about $8 \%$ less than Japanese

- Indian unemployment is 2 times Japan

- Language- in India, Hindi is official national language but English is also subsidiary official language. In addition India has 14 other official languages: Bengali, Telugu, Marathi, Tamil, Urdu,
Gujarati, Malayalam, Kannada, Oriya, Punjabi, Assamese, Kashmiri, Sindhi, and Sanskrit.Japan has only one language -Japanese.

Religion- Most of the Indians strictly follow several cultural practices, rituals and festivals related to individual religions. There are mainly Hindu, Muslim and Christian as well as Sikh religions in India. India celebrates festivals for each religion as national holidays. On the other hand, although there are Shintoism, Buddhism and Christian religions in Japan, basically Japanese are not so religious persons as compared to Indians. There are no religion based national holidays in Japan. 25th December is a working day in Japan.

Table 1 Hofstede Analysis between India and Japan

\begin{tabular}{|c|c|c|}
\hline Hofstede Factor & India & Japan \\
\hline $\begin{array}{l}\text { Uncertainty Avoidance } \\
\text { The extent to which the members of a } \\
\text { culture feel threatened by ambiguous or } \\
\text { unknown situations and have created } \\
\text { beliefs and institutions that try to avoid } \\
\text { these is reflected }\end{array}$ & $\begin{array}{l}\text { India has a medium low preference for } \\
\text { avoiding uncertainty. Indians have a } \\
\text { mentality called as 'Chalta Hai' meaning } \\
\text { anything is ok, or acceptable. For example, it } \\
\text { is ok to be late to meeting, it is ok to be } \\
\text { absent for important events and so on. It is } \\
\text { also ok, if things are not perfect or do not go } \\
\text { as planned. Indians have capacity to be } \\
\text { flexible, resourceful and innovative in } \\
\text { overcoming last minute challenges, and meet } \\
\text { the goal somehow. }\end{array}$ & $\begin{array}{l}\text { Japan is one of the most uncertainty } \\
\text { avoiding countries. Everything has to be } \\
\text { perfect in Japan. For example public } \\
\text { transport runs perfectly on time. In most of } \\
\text { the situations the risks, failure situations } \\
\text { and unusual conditions are thoroughly } \\
\text { researched and prevented or taken care of. } \\
\text { So last minute panic or surprises are almost } \\
\text { impossible in Japanese life. }\end{array}$ \\
\hline
\end{tabular}




\section{Japan and India cultural analysis}

Japan and India are two different cultures. Professor Geert Hofstede, had been one of the leading representatives of intercultural research and studies [8]. Table 1 shows the comparison between India and Japan based on the most important cross cultural factor i.e. Uncertainty avoidance

\section{CCGIRP - approach to solve challenges}

To be able to bridge the gaps and help deal well with these challenges, the authors started a project called as CrossCultural gap improvement research project. Following were the steps in this project.

- Part 1 - Case Studies - Actual interviews of the project managers outsourcing software development to India were recorded and contents analyzed.

- Part 2 - Data Gathering - Cross cultural surveys for IT projects- Project Managers from Japan on Indian Team and Project Managers from India on their counterpart Japanese customer teams were carried out.

- Part 3 - Data Analysis- Analysis of data gathered through surveys and case studies was carried out and suggestions reported which can be used as checklist to further improve way of working.

\section{Case Studies}

As Part 1 of this project, case study interviews were conducted with international project managers in Japan. Some of the interviews are summarized below.

\section{Case Study \#1 - TT}

- $\quad$ Problem of misinterpretation -
○ For example, team working as agile style. Each morning Scrum master has to assign tickets. If Project Manager from Japan says I want to assign this to Indian team, Indian team says ok. There is no answer on the same day, but two days later when we investigate why there is delay, they say it is too difficult, they cannot do this work. When they say 'OK' they did not take it as a responsibility. We need to check on them. So this means that 'OK' is only acknowledge. So Ok is not always ok (laughter).

○ When they say I will try it sounds like they will like to investigate or proceed. But when they say I will try nothing happens, so unless I check tickets, it is not understood.

- $\quad$ Time sense -

○ Difficult. We have 3.5 hours' time difference. We work as agile style, I would like them to work as same as Japan hours. But I heard there are difficulties, so we compromise they come India time 8 AM, which is 11:30 AM Japan time. What happens is manager promises, 8 AM India time, but only $20-30 \%$ members come between $8-830$ and rest come late. So they come to office $2 \mathrm{pm}$ 
JST, it is too late for us, and we cannot keep the agile style.

- When we communicate with mail, and next day there is no reply, sometimes 2 days later we get reply. I send another mail. Please reply me, so even though they do not reply at that time, they reply next week. And of course they apologize but it is waste of time. Indian people expression is polite, then next day they apologize nicely, so I feel kind of pressure because they apologize sincerely.

- Deadline sounds like not having same meaning. When Japanese people say Friday it is Friday morning. When they say early next week they expect Monday morning. If I specify the time very clearly, I think it is impolite.

○ Punctuality -Sometimes they are getting late, $20 \%$ coming to office on time, but all people not coming on time. Sometimes some people do not show up at all.

- When I ask them to come to office early, there is no answer, but after asking many times, I understood that it is dangerous to come very early in the morning. India is not so safe. Company has to prepare transportation. I never imagined that. In Japan I can come to office at 6 AM safely. They should explain frankly what the reason is.

- Infrastructure -

- We have to have pretty often skype meeting, video chat meeting for scrum meeting, but their Wi-Fi is not good, then we have to change to chat conversion, but it is good to see face and have direct face to face conversations. It becomes difficult. We also have a video communication facility called as 'movi Cisco Jabber', and they also have Rakuten account so they should also be able to use it. This happens every day. Video conference is difficult because we can connect but it is terminated pretty often. Must be issue on the India side of network. This fact is already escalated to Indian management, but there is no improvement in situation.

- Language barrier

- Language barrier is no issue, because we both use English. The output (of software) is expected in English. This is effective. The localization team is comfortable with the English deliverable. The language 
issue is not connected with technical

output.

- $\quad$ Skillset

- Some people have very high skill, some do not. We always ask Indian manager to hire good skills like technical leads, but they do not. Many senior people have only project manager skills. So we do not get the contribution in analysis of ticket, so bridge engineering function is weak. We need to have more technical knowledge with the leadership.

\section{Case Study \#2 - HK}

- Language barrier

○ Have strong accent. The way they speak they have strong accent very difficult to understand by Japanese. So for example if they are saying Server it sounds as saruvaru which means monkey in Japanese. We need to take efforts to understand. If the other person is native Indian, never lived abroad, it is really challenging. I keep saying please speak slowly. I have to keep listening I was in Amsterdam and the guy was in Bangalore, even if I say please speak slowly, nothing improves, so I have to continue listening. I let them do the same. Sometimes I get angry. Even if it causes that I cannot understand then I escalate, but I could manage. I can just confirm. Even if they say long sentences, I can convert into small sentences and somehow manage.

- How about the output of software development- is it all English? Is there any gap in technical skills and requirement understanding - Actually the requirement itself is foreign, the base is Japanese, specifications in Japanese, we convert the Japanese requirements to English, by Indian translator. But there was problem. So the output was below expectations. Even there are Indians speaking, reading, writing Japanese, but for them it was difficult to understand what was written in Japanese and hence difficult to deliver the desired output. I had to support. In outsourced projects, understanding of requirements is very valuable. There was gap, but I worked as bridge engineer for them. (Their bridge engineer skill was weak.) From India all delivery is in English language. Then in Japan we do the localization. I find the documents are in 'Indian English'. So sometimes difficult to understand. 
- The deadline is not strict, so when asked when you can finish, they give one date, then when explained in the details, they ask for another date. We are not pushing hard about this. So it depends on how we push. Of course if we push they keep deadline.

- Infrastructure -

- Cisco Jabber -Sometimes they have problem, it is related to Indian infrastructure.

\section{- Communication Skillset}

- Communication between company employees is not good. They are mostly Indians. I do not understand what could be the problem. There is no liaison who knows all and understands technology, like bridge engineer.

○ They have hierarchy structure. If the junior has more knowledge, he/she cannot say to boss. That makes it difficult to get the desired output. Tech Leads should take control, but he is in shadow in my project.

\section{Case Study \#3 - DR}

- Trouble with management -

○ Working with project manager, program manager and the sales manager. The individual engineers did not have proper structure or line of communication with their manager. The Program and Projects managers also expected the team to deliver the product, but they did not create a team to deliver. If they had no knowledge, they could ask question. But they did not.

During weekly project management meeting, determine the health of the project, it was reported healthy despite of the fact that many issues were there. They did not consider those as issues. It cannot be a cultural or language difference because we all spoke in English, agreed to specific milestones. There is nothing to point to either Japanese or Indian culture, it is just difference in Management style.

- Escalation was done on both company sides to higher management. When we escalated, first to the program manager above the project manager. He would join the call, but would say this is not issue. Or would say let us follow different method? Just a covering up of the project manager or justifying mistakes.

- We went to topmost point of contact we had for the project. It also went to the Japan side sales manager. But each time 
we got only excuses and blames. All responses were like 'this is not our fault' type. So final response was to cut out the management on the vendor side and to work with the engineers directly. There is no project manager in India. We brought all of them to India. Gave up on the offshore model. This was cost of the communication issue. Now no communication gap, tools are all smooth and delivery is good.

- To improve this, there should be an SLA with a condition indicating that if they fail to deliver, then there is some kind of a penalty. Current contract only protects the vendor, but no protection of Rakuten. We have no way to make sure that they give us the product we desire. We are paying extra money but we are not going to get that back. We do not have penalties for no or poor delivery. We need to have penalties on both sides.

- $\quad$ Time sense -

- Lot of questions we got from the team we got later in the day, and we tried to mitigate by having query logs, and daily conversations with the team. But the team did not use it regularly. They took longer to come up with a query. E.g. we expected them to come up with queries within 3 days, but they came back only just before delivery.

- Requirement definition

○ Requirements were $95 \%$ defined. What we did have was clear enough and good for development. It was created by CITD for developers. We had enough time for them to go through the requirements and address issues. Due to visa issues we lost a lot of time. The team had only one person to go to when they had questions. That caused gap.

India Japan way of working Survey

As Part 2 of this project, a two surveys were conducted. Survey \#1 focused on the international managers from Japan outsourcing to India. 42 persons responded to Survey \#1. Survey \#2 was for project managers from India. 15 persons responded to Survey \#2. Following Table 2 Survey Data Analysis shows the comparative data collected in both surveys.

\section{Findings - Problems and Improvement suggestions}

Looking at the case studies and the survey data analysis, the problems and improvement suggestions on major issues for each country can be detailed as below table 3 . 
Table 2 Survey Data Analysis

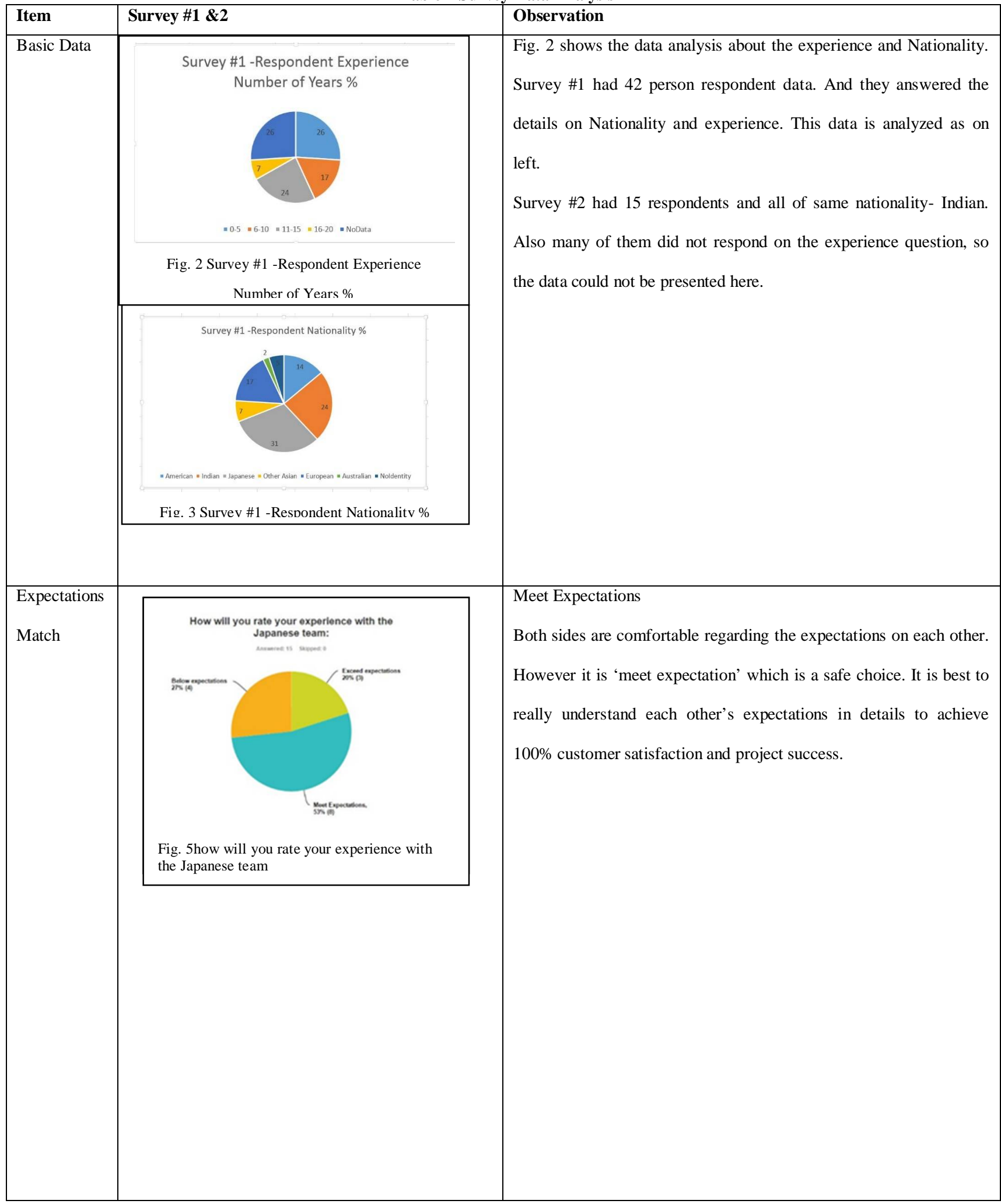




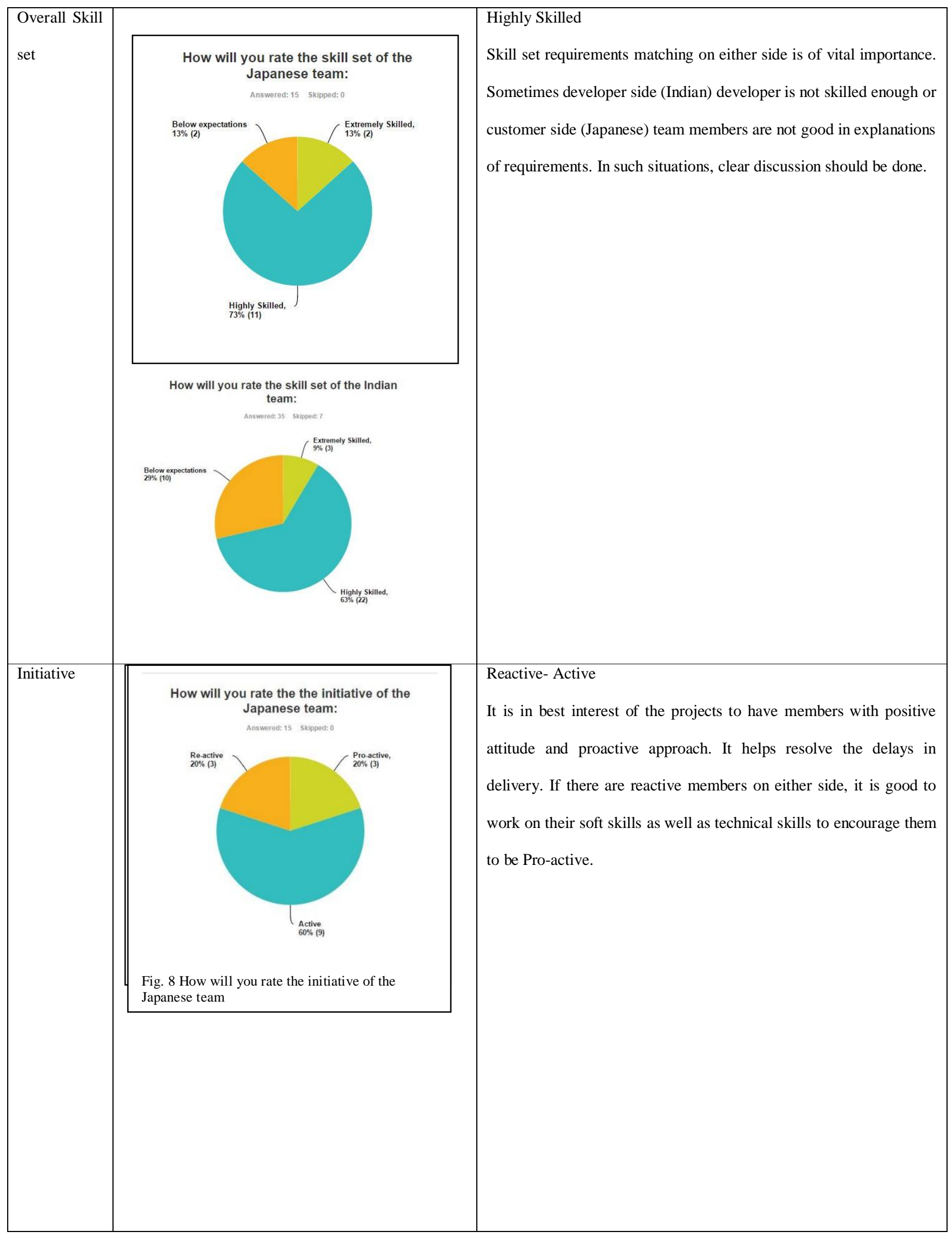




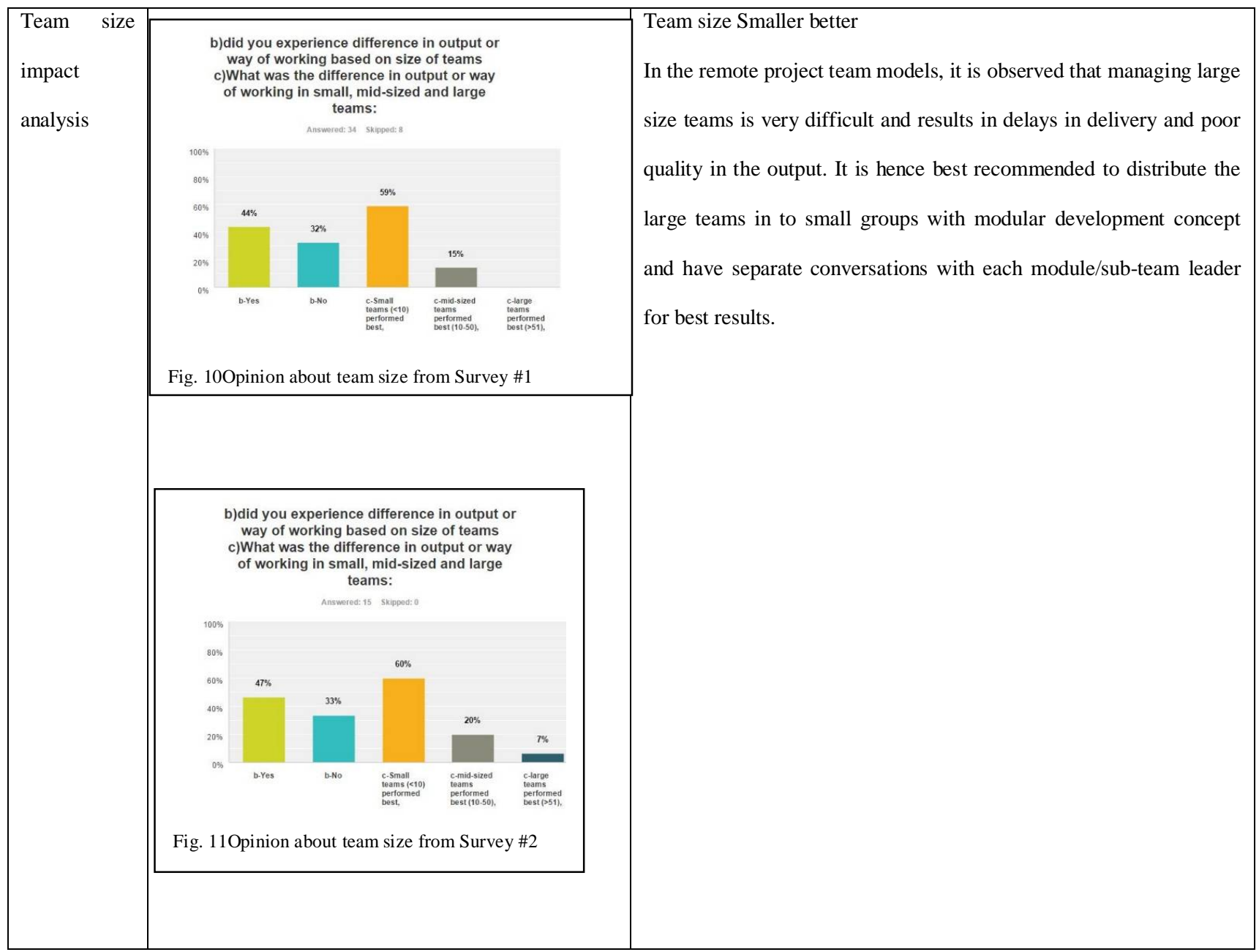

Table 3 Detailed suggestions for improvement

\begin{tabular}{|l|l|l|}
\hline \multicolumn{2}{|c|}{ Problems } & \multicolumn{1}{|c|}{ Japan to India } \\
\hline $\begin{array}{l}\text { Problem of transparency -saying 'no } \\
\text { problem' but actually having many problems }\end{array}$ & $\begin{array}{l}\text { Ask specific questions related to } \\
\text { assignment and do not accept "No } \\
\text { Problem" as answer }\end{array}$ & $\begin{array}{l}\text { Study the assignment clearly before } \\
\text { responding with respect to time commitment. } \\
\text { Ask questions. }\end{array}$ \\
\hline $\begin{array}{l}\text { Problem of misinterpretation - saying 'I will } \\
\text { try' which actually means 'I have no } \\
\text { intentions of taking this up, I am just being } \\
\text { polite not to refuse out rightly" }\end{array}$ & $\begin{array}{l}\text { Ask specific questions related to } \\
\text { assignment and do not accept "I will try" as } \\
\text { answer }\end{array}$ & $\begin{array}{l}\text { If the assignment is not possible, just state } \\
\text { your challenges in meeting the time or quality } \\
\text { or delivery (content) commitment. } \\
\text { Ambiguous answers make it difficult to judge. }\end{array}$ \\
\hline $\begin{array}{l}\text { Problem of time sense 'I will deliver on } \\
\begin{array}{l}\text { Friday' but actual delivery happening over } \\
\text { weekend before Monday morning your } \\
\text { office hours. }\end{array}\end{array}$ & $\begin{array}{l}\text { Specify expected time of delivery clearly. } \\
\text { Do not assume. }\end{array}$ & $\begin{array}{l}\text { Confirm when the delivery is expected. If not } \\
\text { possible to commit to that, state clearly with } \\
\text { facts. }\end{array}$ \\
\hline
\end{tabular}


Problem with hospitality - Being excessively hospitable with food and parties as well as socializing, as if to filling in the lack of professionalism and output at the work.

Problem with punctuality - Taking start and end times of meetings or activities not so seriously, delays of 30 minutes can go without excuse or apologies. parties or dinners offered by host. If convenient, please relax and enjoy Indian cultural hospitality.
If not convenient, learn to say no to the

Confirm if the hospitality is not

overwhelming to the guest. When going from Japan to India, the guest is already facing many challenges like food, weather, language etc. So it may not be convenient.

Punctuality is at the base of Japanese business. So Improvement on part of Indian team is necessary.

State expectations clearly and watch for improvement
Problem with infrastructure - Not considering the needs of foreign guests enough e.g. no solution to power cut (electricity), no internet connection/Wi-Fi, telephone or other relevant communication facilities.

\section{State expectations clearly about} requirements like $\mathrm{Wi}-\mathrm{Fi}$ and telephone etc. so provision can be made on Indian side. Do not assume facilities will be same as in Japan
Confirm expectations on technology side. Japan is very advanced and there are no power failures or network-down situations.

\begin{tabular}{|c|c|c|}
\hline \multirow{2}{*}{$\frac{\text { Problems }}{\text { ndia to Japan }}$} & \multicolumn{2}{|c|}{ Improvement Suggestions } \\
\hline & Japan & India \\
\hline $\begin{array}{l}\text { Problem of micromanagement -would like } \\
\text { to know smaller details of assignment in } \\
\text { every aspect, although it is irrelevant as the } \\
\text { project is outsourced. }\end{array}$ & $\begin{array}{l}\text { Specify clearly about timeline and delivery } \\
\text { quality expectations and get the } \\
\text { commitment to avoid micromanagement. }\end{array}$ & $\begin{array}{l}\text { Leader should stick to commitment and } \\
\text { establish trust with Japanese customer so need } \\
\text { for micromanagement will not be felt. }\end{array}$ \\
\hline $\begin{array}{l}\text { Problem of being perfectionist- criticizing on } \\
\text { smallest part of the work which you might } \\
\text { find insignificant }\end{array}$ & $\begin{array}{l}\text { Specify clearly about delivery quality } \\
\text { expectations and get the commitment. } \\
\text { Include interim formal checking couple of } \\
\text { times (not too much) to avoid surprises in } \\
\text { the end. }\end{array}$ & $\begin{array}{l}\text { Be prepared for interim checks and do not } \\
\text { take them lightly. If the interim quality is } \\
\text { poor, there will be doubt for the final } \\
\text { deliverable, and criticism is unavoidable. }\end{array}$ \\
\hline $\begin{array}{l}\text { Problem of time sense }- \text { too } \\
\text { stringent, delivery on Friday means Friday } \\
\text { Japan time } 9 \text { AM }\end{array}$ & $\begin{array}{l}\text { Specify expected time of delivery clearly. } \\
\text { Do not assume. }\end{array}$ & $\begin{array}{l}\text { Confirm when the delivery is expected. If not } \\
\text { possible to commit to that, state clearly with } \\
\text { facts. }\end{array}$ \\
\hline $\begin{array}{l}\text { Problem with socializing - not friendly at or } \\
\text { off work, makes difficult to break the ice, } \\
\text { work long durations on Japanese projects. }\end{array}$ & $\begin{array}{l}\text { Japanese team should have more friendly } \\
\text { approach towards the team members when } \\
\text { interacting face to face although it is not so } \\
\text { much of practice in Japan. }\end{array}$ & $\begin{array}{l}\text { Indian team should lower expectations on } \\
\text { socializing and focus more on delivery, ask } \\
\text { more questions to understand deeply and to } \\
\text { avoid long hours. }\end{array}$ \\
\hline $\begin{array}{l}\text { Problem with punctuality - panicking if late } \\
\text { by few minutes }\end{array}$ & $\begin{array}{l}\text { State expectations clearly and watch for } \\
\text { improvement }\end{array}$ & $\begin{array}{l}\text { Punctuality is at the base of Japanese } \\
\text { business. So Improvement on part of Indian } \\
\text { team is necessary. }\end{array}$ \\
\hline
\end{tabular}




\begin{tabular}{|l|l|l|l|} 
Problem with infrastructure - Not & State expectations clearly about & Confirm expectations on technology side. \\
considering that infrastructure in India is not & requirements like Wi-Fi and telephone etc. & Japan is very advanced and there are no \\
as advanced as in Japan (e.g. electricity & so provision can be made on Indian side. & power failures or network-down situations. \\
power cutoff on weekly basis) & Do not assume facilities will be same as in & \\
& Japan & \\
\hline
\end{tabular}

\begin{tabular}{l}
$\begin{array}{l}\text { Have clarity in communication. } \\
\text { Do not assume. Periodically reconfirm } \\
\text { understanding on either side. }\end{array}$ \\
$\begin{array}{l}\text { Explain cultural aspect of being good host } \\
\text { (Omotenashi in Japanese) }\end{array}$ \\
$\begin{array}{l}\text { Confirm the seamlessness of facilities } \\
\text { Internet - LAN, WIF } \\
\text { Audlo \& VIdeo conferencing } \\
\text { File sharing }\end{array}$ \\
$\begin{array}{l}\text { Take it easy. Accept cultural difference. } \\
\text { Trust each other } \\
\text { Make simple and easy processes }\end{array}$ \\
\hline $\begin{array}{l}\text { Green - India to strengthen } \\
\text { Red - Japan to improve } \\
\text { Blue - both the teams to work } \\
\text { together. }\end{array}$
\end{tabular}

\section{Conclusion}

In this research paper it is seen that due to natural cultural differences between India and Japan, although both are Asian countries, there are gaps and mismatch of expectations during international information technology projects. The case studies of Rakuten outsourced projects as well as the survey results indicate clear improvement requirements on both sides as summarized here. Clarity in communications, understanding cultural differences, confirmation of the readiness of infrastructure on Indian side and respecting the time commitments are considered as topmost targets.

With this research it is hoped that not only the Rakuten internal project managers, but all the persons in leadership role working between India and Japan would find information applicable to their situations. It is also hoped that the future leaders from India consider these feedbacks valuable for them and develop their appropriate soft skills and communication processes.

\section{References}

1. https://en.wikipedia.org/wiki/Rakuten

2. http://www.techopedia.com/definition/23169/busi ness-to-business-to-consumer-b2b2c

3. http://www.retailingtoday.com/article/rakuten $\% \mathrm{E} 2$ $\% 80 \% 99$ s-expanding-footprint-reaches-america

4. http://global.rakuten.com/corp/investors/policy/str ength/business_model.html

5. http://global.rakuten.com/corp/about/overview.ht $\mathrm{ml}$

6. Rakuten Qualitative Info and Financial Summary (Full) Annual Report for FY2014

7. http://www.techrepublic.com/blog/10-things/10things-you-should-know-about-working-with-anoffshore-team/

8. http://geert-hofstede.com/about-us.html

9. http://www.cio.com/article/2391721/outsourcing/7 -tips-to-offshore-agile-development.html

10. Risks Identification in an Offshore - Onshore Model based IT Engagement International Journal of Computer Applications (0975 - 888) Volume 48- No.14, June 2012 
11. https://josephvargheese.wordpress.com/tag/agilemethodology-onsite-offshore-model/

\section{Note}

The authors gratefully thank the senior management of Rakuten, Inc, for their kind permission to conduct this research, as well as to the interviewees in project management who generously shared their expertise with us.

\section{Appendix}

\section{List of Figures}

1. Fig.1 Rakuten Ichiba Japanese website.

2. Fig. 2 Survey \#1 -Respondent Experience Number of Years \%

3. Fig. 3 Survey \#1 -Respondent Nationality \%

4. Fig. 4 How will you rate your experience with the Indian team

5. Fig. 5 How will you rate your experience with the Japanese team

6. Fig. 6 How will you rate the skill set of the Indian team

7. Fig. 7 How will you rate the skill set of the Japanese team:

8. Fig. 8 How will you rate the initiative of the Indian team

9. Fig. 9 How will you rate the initiative of the Japanese team

10. Fig. 10 Opinion about team size from Survey \#1

11. Fig. 11 Opinion about team size from Survey \#2

12. Fig. 12 Japan India way of working improvement proposal

\section{List of Tables}

1. Table 1 Hofstede Analysis between India and Japan

2. Table 2 Survey Data Analysis

3. Table 3Detailed suggestions for improvement 